OPEN ACCESS

Edited by:

Romuald Lipcius,

College of William \& Mary,

United States

Reviewed by:

Putu Liza Mustika,

James Cook University, Australia

Alice E. Hall,

Bournemouth University,

United Kingdom

*Correspondence:

Andrew Thale

andrew@blackbeardbiologic.com

Specialty section:

This article was submitted to

Marine Conservation and

Sustainability,

a section of the journa

Frontiers in Marine Science

Received: 16 November 2018

Accepted: 30 July 2019

Published: 21 August 2019

Citation:

Thaler A, Parsons ECM, de Vos A

Rose NA, Smith C and Fretz D (2019)

Bot Meets Whale: Best Practices for

Mitigating Negative Interactions

Between Marine Mammals and

MicroROVs. Front. Mar. Sci. 6:506.

doi: 10.3389/fmars.2019.00506

\section{Bot Meets Whale: Best Practices for Mitigating Negative Interactions Between Marine Mammals and MicroROVs}

\author{
Andrew Thaler ${ }^{1,2 *}$, E. C. M. Parsons ${ }^{3}$, Asha de Vos ${ }^{4}$, Naomi A. Rose ${ }^{5}$, Courtney Smith ${ }^{6}$ \\ and Dominik Fretz ${ }^{7}$ \\ ${ }^{1}$ Blackbeard Biologic: Science and Environmental Advisors, St. Michaels, MD, United States, ${ }^{2}$ Center for Environmental \\ Science, Horn Point Laboratory, University of Maryland, Cambridge, MD, United States, ${ }^{3}$ Institute of Biodiversity, Animal \\ Health and Comparative Medicine, Glasgow University, Glasgow, Scotland, ${ }^{4}$ Oceanswell, Colombo, Sri Lanka, ${ }^{5}$ Animal \\ Welfare Institute, Washington, DC, United States, ${ }^{6}$ Department of Environmental Science and Policy, George Mason \\ University, Fairfax, VA, United States, ${ }^{7}$ OpenROV, Berkeley, CA, United States
}

Keywords: microROV, marine mammals, whales, entanglement, underwater drones

\section{INTRODUCTION}

Low-cost, portable, observation-class, underwater remotely operated vehicles (microROVs), which can be transported and operated by a single user, are increasingly common tools in scientific, industrial, commercial, and recreational ocean application. Over the last decade, the use of microROVs has boomed; four microROV manufacturers were poised to ship over 10,000 "underwater drones" in 2018 (Thaler, personal observation). This nascent industry provides an affordable underwater observation solution for marine science, conservation, education, and citizen science programs, as well as community groups and other stakeholders wishing to conduct independent marine environmental surveys and provides users with an opportunity to view marine wildlife with minimal disturbance (Figure 1).

This surge in the availability of microROVs also presents several new challenges to marine species. As more robots enter the water, often in the hands of inexperienced recreational users, there is increased potential for detrimental human/marine mammal interactions. MicroROVs are highly portable and have been identified as potential vectors for invasive species (Thaler et al., 2015). MicroROVs are also capable of causing harm to fragile marine ecosystems from contact with sensitive structures or tether entanglement. One possible outcome of increasing recreational use of microROVs is the increased harassment of marine mammals. The availability of new tools that allow people to approach and view marine mammals while maintaining their own safety has, if managed poorly, the potential to significantly alter the behavior of marine mammals (Higham et al., 2014; Smith et al., 2016). An example of this is provided by the whale and dolphin watching industry, which has developed rapidly world-wide, in some cases with demonstrably negative impacts on targeted populations (Bejder et al., 2006; Barragán-Barrera et al., 2017). Consequently, international policy bodies have been working toward a universal set of best practice guidelines for cetacean viewing over the past decade (e.g., Iñíguez, 2013; ACCOBAMS, 2016). Though not directly comparable, similar discussions have happened over the use of uncrewed aerial vehicles operated in close proximity to marine mammals (Thaler, 2014). 


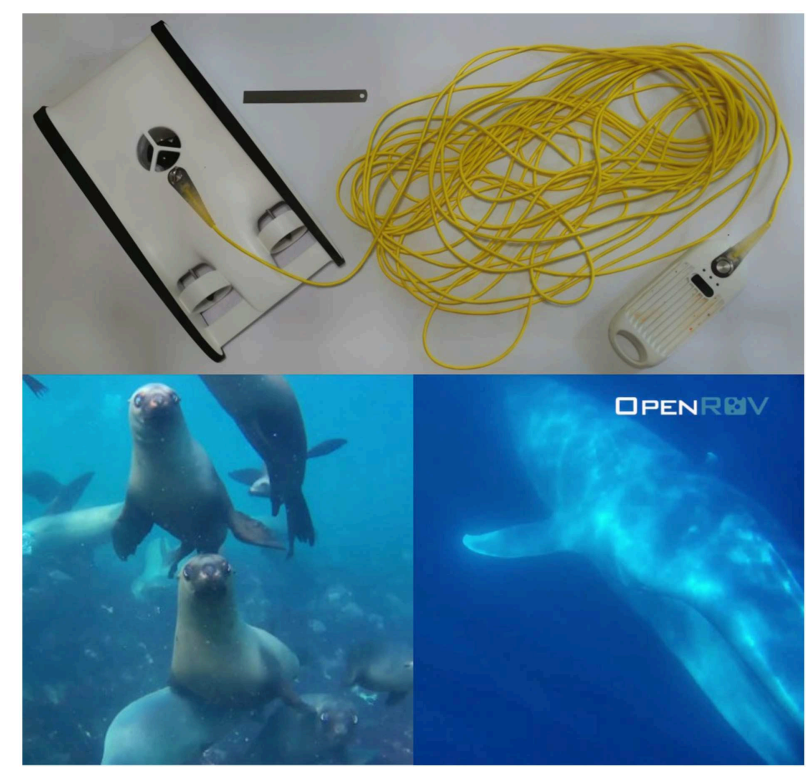

FIGURE 1 | Top: An example of a microROV system (OpenROV Trident) with $20 \mathrm{~m}$ tether and topside control system. $15 \mathrm{~cm}$ ruler provided for scale. Bottom left: Sea lions investigate a microROV off the California coast. Bottom right: a blue whale approaches and swims past a stationary microROV during a commercial whale watching excursion near Moss Landing, California. All photos used with permission.

To better understand the potential risks and to establish an anticipatory framework to minimize negative interactions between MicroROV operators and marine mammals, we, a group of six experts in microROVs and/or marine mammal tourism, conservation, and ecology, conducted a self-guided series of surveys to better identify the most likely and most damaging sources of harmful interactions between microROVs and marine mammals. We then established a set of best practice guidelines for the responsible operation of microROVs in the presence of marine mammals. Those guidelines, elaborated below, can be summarized as:

1. Educate users about the potential negative consequences of microROV operation in the presence of marine mammals.

2. Maintain situational awareness to avoid unintentional contact.

3. Maintain safe distances and avoid intentional contact.

4. Use microROVs as a tool to reduce the number of humans and large passenger vehicles on or in the water.

5. Avoid deployment where marine mammals are already active in an area.

\section{METHODOLOGY}

We deployed a highly-abridged version of the Delphi method, an iterative survey technique that aims to establish general consensus (Sumsion, 1998), amongst ourselves. A two-stage online survey, distributed among the six co-authors of this paper, was conducted using Google (Mountain View, California) software. This approach was implemented in order to identify broad agreement among co-authors, as well as critical points of disagreement and, as group discussion had to be coordinated across three continents, to establish an initial consensus framework that permitted more efficient discourse. While this approach does not produce a de facto "correct" answer, it does generate a reliable assessment of group opinion, from which consensus can emerge (Hasson et al., 2000).

In Survey 1, the authors were provided with an introduction to the iterative study design and asked to independently provide their assessment of the potential impacts of microROVs on marine mammals. We then ranked the likelihood of an impact occurring and the likelihood that those impacts would cause injury to, or behavioral change in, marine mammals using a fivepoint Likert scale. We also provided additional potential impacts.

In Survey 2, the authors reviewed the results of Survey 1 and considered whether we agreed with the emergent consensus. The outcome of these surveys was used as a launch point to further discuss and clarify the potential impacts of microROV operation in close proximity to marine mammals. Our conclusions and recommendations, however, represent a consensus expert opinion rather than empirically-tested observation and should be interpreted as such.

\section{ETHICS STATEMENT}

This research did not require Institutional Review Board approval. Participation was self-selected, and surveys did not include sensitive personal questions. As this process was implemented to assess consensus among the co-authors of this paper, anonymity could not be maintained.

\section{POTENTIAL IMPACTS}

For harassment that includes direct contact between marine mammals and microROVs, we considered collisions and tether entanglement most likely to occur, while ingestion was considered to be relatively less likely. If the microROV is lost due to tether breakage, it could be ingested if it is within an important feeding area, particularly for baleen whales that engage in feeding behaviors which have resulted in contact with unsuspecting humans at the surface (Pappas, 2019). Collisions were not expected to be as likely to cause injury as either entanglements or ingestion, and the size of the animal was expected to be a major determinant in the potential for injury as the relatively small mass of the microROV is unlikely to cause direct harm to an animal several hundred orders of magnitude larger than it.

For harassment that results in behavioral change through indirect contact with marine mammals, light and noise produced by the microROV were considered most likely to cause impacts and alter behavior. The mere presence of the microROV was also considered likely to alter behavior for some marine mammals, such as sea lions (Zalophus spp.), that are curious and may follow or investigate them (de Vere et al., 2017). Though there are no current studies on how light and noise produced by microROVs can impact marine life, one earlier 
study demonstrated that the presence of a large research ROV had a detrimental effect on the feeding behavior of some animals (Spanier et al., 1994).

Although the impacts of operator behavior can result in both direct and indirect contact and harassment, we considered operator behavior as a separate category. Actions taken by the operator, such as whether or not to approach a marine mammal, are intentional impacts, rather than innate features of the equipment. Active, intentional harassment (e.g., pursuit/chasing of marine mammals) facilitated by access to microROVs was considered likely to occur and likely to result in both injuries and behavioral changes. Increased density of both boats and equipment in the water was also considered to have a high potential for impact. The presence of the microROVs was also considered likely to increase habituation to people, resulting in negative behavioral changes. Operator actions can also result in unintentional impacts, such as a marine mammal becoming entangled in the tether.

We collectively agreed that as microROVs become more available, they are more likely to be in the hands of untrained users, which can confound best practices and requires general user education. In addition, we determined that, while it may seem as if a certain number of boat lengths [a standard measuring tool used by marine mammal researchers (Dawson et al., 2008)] is the appropriate distance to remain from a marine mammal during directed activities, the submerged microROV may be much closer. This scenario could present challenges for enforcement officers, who can observe human behavior on the surface but may not be able to track submerged equipment.

\section{GUIDELINES AND DISCUSSION}

Based on the identified risks, we established a set of guidelines for microROV operators to minimize their potential impact on marine mammals. While several of these recommendations mirror existing wildlife viewing regulations that protect marine mammals in jurisdictions such as the exclusive economic zone of the United States, we have intentionally structured these guidelines to represent consensus best practices regardless of the regulatory environment in which the microROV user operates.

\section{Education}

Central to any mitigation strategy involving diverse stakeholders, ranging from professional to recreational, is user education. The following are critical to establishing a responsible user community: Ensuring all potential microROV users (1) not only understand the laws and regulations for wildlife viewing that apply to the jurisdiction in which they are operating, but understand why those regulations are in place; and, most importantly, (2) have internalized a stewardship ethic that motivates them to respect the rationale behind those regulations even when operating in regions where those regulations are not enforced. This is most effective when it occurs at point-of-sale or registration of the microROV. Thus, while the additional four guidelines relate to the user, this first one relates to the manufacturer. To most effectively convey the potential harm that microROVs could pose to marine mammals, the manufacturers are best positioned to educate their user base by providing informational material with each microROV sale.

\section{Avoid Unintentional Contact by Maintaining Situational Awareness}

As some of the most disruptive outcomes of interaction between marine mammals and microROVs are unintentional contact, users must maintain comprehensive situational awareness of their operating site, the location of their tether, and the presence of any marine mammals. When an animal-initiated approach is observed, users should first confirm that the microROV tether is not in the path of approach and then either remain stationary with thrusters powered down until the animal passes or remove the vehicle from the water while causing minimal disturbance.

\section{Avoid Intentional Contact by Maintaining a Safe Distance and Piloting Responsibly}

When operated in close proximity to marine mammals, microROVs should be treated no differently than any other vehicle. Intentional contact with marine mammals is not only highly disruptive but is illegal in some countries (Kindt and Wintheiser, 1985). MicroROV operators should familiarize themselves with local wildlife viewing regulations, always maintain a safe distance (50 to $100 \mathrm{~m}$; distances can be estimated, where water visibility allows, by placing highly visible markers on the tether to act as a scale) when piloting a microROV in areas where marine mammals are present and maintain constant awareness over the location of both the robots and marine mammals. Where local regulations or professional standards exist for local tourism, microROVs should not get closer than the distances stipulated by local marine mammal approach standards. Any direct contact between a microROV and a marine mammal should be treated as an unacceptable encounter and microROV operations should cease immediately. Maintaining a safe distance will also mitigate the impact of noise produced by the microROV.

\section{Treat microROVs as a Tool to Reduce, Rather Than Increase, Vehicle Density}

MicroROVs present a powerful opportunity to allow a large number of people to safely view marine mammals. Because of this, it may be tempting to deploy multiple microROVs in regions where marine mammals are known to aggregate, thus increasing the risk of contact and behavioral alterations to the target species. MicroROVs should be treated as tools to reduce vehicle density by allowing multiple operators and viewers to use a single microROV feed as an alternative to many divers in the water or numerous tour boats. As multiple microROVs operating in a small area also create hazards for the devices, operators should adopt standards and protocols (such as "first-come, firstserved" commonly used at popular SCUBA diving locations) to minimize microROV density. 


\section{Minimize Deployment in Regions of Known Ecological Importance to Marine Mammals}

There are a number of locations that have been designated as Marine Protected Areas or identified as "hotspots" for marine mammals, year-round and seasonally, such as Kealakekua Bay in Hawaii (spinner dolphins; Stenella longirostris; Timmel et al., 2008; Tyne et al., 2015; Heenehan et al., 2017) or Samaná Bay in the Dominican Republic (humpback whales, Megaptera novaeangliae; Mattila et al., 1994; Betancourt et al., 2012; Gleason and Parsons, 2018). In addition, there are locations where marine mammals are reliably sighted and engaged in normal behaviors, such as foraging, mating, or nursing (e.g., California sea lions, Zalophus californianus, in the Channel Islands, and northern elephant seals, Mirounga angustirostris, at Año Nuevo State Park, both in California; Heath and Perrin, 2009; Hindell and Perrin, 2009). Operators should refrain from deploying microROVs in such areas, as well as in areas where marine mammals are present in large numbers. In cases where the microROV is already in the water, operators should recall the device if it becomes likely that direct or indirect contact could occur. Operators should always refrain from pursuing or otherwise interacting with marine mammals. In cases where rare and vulnerable species are observed (and particularly when engaged in critical behaviors such as forging, mating, or nursing young), microROV users should make every effort to remove their equipment from the water without causing additional disturbance.

\section{CONCLUSION}

Low-cost microROVs present tremendous opportunities for marine research, conservation, exploration, and recreation. With these opportunities comes a responsibility to ensure that microROV users minimize harm to the marine environment.

\section{REFERENCES}

ACCOBAMS (2016). Commercial Cetacean Watching Activities in the ACCOBAMS Area (Resolution No. ACCOBAMS-MOP6/2016/Res.6.20).

Barragán-Barrera, D. C., May-Collado, L. J., Tezanos-Pinto, G., Islas-Villanueva, V., Correa-Cárdenas, C. A., and Caballero, S. (2017). High genetic structure and low mitochondrial diversity in bottlenose dolphins of the Archipelago of Bocas del Toro, Panama: a population at risk? PLoS ONE 12:e0189370. doi: 10.1371/journal.pone.0189370

Bejder, L., Samuels, A., Whitehead, H., Gales, N., Mann, J., Connor, R., et al. (2006). Decline in relative abundance of bottlenose dolphins exposed to long-term disturbance. Conserv. Biol. 20, 1791-1798. doi: 10.1111/j.1523-1739.2006.00540.x

Betancourt, L., Herrera-Moreno, A., and Beddall, K. (2012). "Spatial distribution of humpback whales (Megaptera novaeangliae) in Saman? Bay, Dominican Republic," in Paper SC/64/O12 Submitted to the Intl Whal Commn Scientific Committee (Panama City).

Dawson, S., Wade, P., Slooten, E., and Barlow, J. (2008). Design and field methods for sighting surveys of cetaceans in coastal and riverine habitats. Mam. Rev. 38, 19-49. doi: 10.1111/j.1365-2907.2008.00119.x

de Vere, A. J., Lilley, M. K., and Highfill, L. (2017). Do pinnipeds have personality? Broad dimensions and contextual consistency of behavior in harbor seals (Phoca vitulina) and California sea lions (Zalophus californianus). Int. J. Comparat. Psychol. 30, 1-15.
As this nascent industry is still largely unregulated, it is up to the users and manufacturers to promote responsible operation of microROVs around marine mammals. By following this preliminary and evolving set of guidelines, microROV users can mitigate or minimize potential harmful interactions with marine mammals from the outset of microROV use expansion. We encourage all microROV users to incorporate these guidelines into their dive operations and encourage microROV manufactures to provide educational materials emphasizing these guidelines at point-of-sale for their customers.

\section{AUTHOR CONTRIBUTIONS}

AT and DF conceived the study. AT designed and implemented the survey. AT, EP, AdV, NR, CS, and DF participated in discussion, guideline development, manuscript drafting, and manuscript revisions.

\section{FUNDING}

AT recognizes funding from Patreon and OpenROV to support this work. AdV recognizes funding from the Pew Charitable Trusts. NR recognizes funding from the Animal Welfare Institute to support her work on this manuscript.

Open-access publication fee will be provided by Blackbeard Biologic, a private environmental consulting firm wholly owned by AT.

\section{ACKNOWLEDGMENTS}

We thank Dr. Amy Freitag, Dr. Stacy Baez, and David Lang for early discussions while developing this manuscript, as well as 2 reviewers.

Gleason, C. M., and Parsons, E. C. M. (2018). To educate or not to educate: how the lack of education programs on whale-watching vessels can impact whale conservation and tourism in the Dominican Republic. Tour. Mar. Environ. 13, 2-3. doi: 10.3727/154427318X15225522881013

Hasson, F., Keeney, S., and McKenna, H. (2000). Research guidelines for the delphi survey technique. J. Adv. Nurs. 32, 1008-1015. doi: 10.1046/j.1365-2648.2000.t01-1-01567.x

Heath, C. B., and Perrin, W. F. (2009). "California, Galapagos, and Japanese sea lions," in Encyclopedia of Marine Mammals, 2nd Edn, eds W. F. Perrin, B. Würsig, and J. G. M. Thewissen (New York, NY: Academic Press), 170-176.

Heenehan, H., Van Parijs, S., Bejder, L., Tyne, J., and Johnston, D. (2017). Differential effects of human activity on Hawaiian spinner dolphins in their resting bays. Glob. Ecol. Conserv. 10, 60-69. doi: 10.1016/j.gecco. 2017.02.003

Higham, J., Bejder, L., and Williams, R. (2014). Whale-Watching: Sustainable Tourism and Ecological Management. New York, NY: Cambridge University Press.

Hindell, M. A., Perrin, W. F. (2009). "Elephant seals," in Encyclopedia of Marine Mammals, 2nd Edn, eds W. F. Perrin, B. Würsig, and J. G. M. Thewissen (New York, NY: Academic Press), 364-368.

Iñíguez, M. (2013). Responsible whale watching and whale welfare. Anim. Welfare 22, 113-115. doi: 10.7120/09627286.22.1.113

Kindt, J. W., and Wintheiser, C. J. (1985). The conservation and protection of marine mammals. U. Haw. L. Rev. 7, 301. 
Mattila, D. K., Clapham, P. J., Vasquez, O., and Bowman, R. S. (1994). Occurrence, population composition, and habitat use of humback whales in Samana Bay, Dominican Republic. Can. J. Zool. 72, 1898-1907. doi: 10.1139/ z94-258

Pappas, S. (2019). What a Fluke! Man Ends Up in Whale's Mouth. Live Science. Available online at: https://www.livescience.com/64969-whale-almostswallows-man.html (accessed June 17, 2019).

Smith, C. E., Sykora-Bodie, S. T., Bloodworth, B., Pack, S. M., Spradlin, T. R., and LeBoeuf, N. R. (2016). Assessment of known impacts of unmanned aerial systems (UAS) on marine mammals: data gaps and recommendations for researchers in the United States. J. Unman. Veh. Sys. 4, 31-44. doi: 10.1139/juvs-2015-0017

Spanier, E., Cobb, J., and Clancy, M. (1994). Impacts of remotely operated vehicles (ROVs) on the behavior of marine animals: an example using American lobsters. Mar. Ecol. Prog. Series. 104, 257-266. doi: 10.3354/ meps 104257

Sumsion, T. (1998). The delphi technique: an adaptive research tool. Br. J. Occup. Ther. 61, 153-156. doi: 10.1177/030802269806100403

Thaler, A. D. (2014). Drones Would Revolutionize Oceanic Conservation, If They Weren't Illegal. Motherboard. Available online at: https://www.vice.com/en_us/ article/vvbzg9/drones-would-revolutionize-whale-watching-if-they-werentillegal

Thaler, A. D., Freitag, A., Bergman, E., Fretz, D., and Saleu, W. (2015). Robots as vectors for marine invasions: Best practices for minimizing transmission of invasive species via observation-class ROVs. Trop. Conser. Sci. 8, 711-717. doi: $10.1177 / 194008291500800308$
Timmel, G., Courbis, S., Sargeant-Green, H., and Markowitz, H. (2008). Effects of human traffic on the movement patterns of Hawaiian spinner dolphins (Stenella longirostris) in Kealakekua Bay, Hawaii. Aquat. Mamm. 34, 402-411. doi: 10.1578/AM.34.4.2008.402

Tyne, J. A., Johnston, D. W., Rankin, R., Loneragan, N. R., and Bejder, L. (2015). The importance of spinner dolphin (Stenella longirostris) resting habitat: implications for management. J. Appl. Ecol. 52, 621-630. doi: 10.1111/1365-2664.12434

Conflict of Interest Statement: AT is the CEO of Blackbeard Biologic: Science and Environmental Advisors. AT and DF are contracted by OpenROV, a manufacturer of microROVs. OpenROV did not have input into study development nor did they review this manuscript prior to submission. Representatives from OpenROV did participate in early discussion during the conception of this study.

The remaining authors declare that the research was conducted in the absence of any commercial or financial relationships that could be construed as a potential conflict of interest.

Copyright (c) 2019 Thaler, Parsons, de Vos, Rose, Smith and Fretz. This is an openaccess article distributed under the terms of the Creative Commons Attribution License (CC BY). The use, distribution or reproduction in other forums is permitted, provided the original author(s) and the copyright owner(s) are credited and that the original publication in this journal is cited, in accordance with accepted academic practice. No use, distribution or reproduction is permitted which does not comply with these terms. 